\title{
Pathologic Complete Response in HER2-Positive Breast Cancer Patients Receiving Trastuzumab in Neoadjuvant Setting
}

\author{
Fareeha Sheikh1', Adil Nazir1', Samia Yasmeen¹, Farhana Badar2, Usman Ahmad¹ and Neelam Siddiqui1
}

\begin{abstract}
Objective: To compare the pathological complete response in human epidermal growth factor receptor type 2 (HER-2) positive breast cancer patients getting neoadjuvant chemotherapy with or without trastuzumab.

Study Design: Retrospective randomised double-arm observational study.

Place and Duration of Study: Shaukat Khanum Memorial Cancer Hospital and Research Centre, Lahore, from 2008 to 2016.

Methodology: HER2-positive, lymph node positive, breast cancer patients receiving neoadjuvant chemotherapy (NACT) were retrospectively observed. Patients getting neoadjuvant trastuzumab, fulfilling the inclusion criteria were studied. The comparison group included randomly selected equal number of HER2-positive breast cancer patients having similar tumor characteristics, getting NACT only. Pathological complete response (pCR) was defined as no residual invasive or in situ residual tumor in breast tissue, or in the lymph nodes. One hundred and fifty-six patients were studied. Eighty-nine patients with HER2-positive disease received trastuzumab preoperatively. Sixty-four $(n=64)$ patients received the complete standard dose of neoadjuvant trastuzumab along with chemotherapy. Almost equal number of patients $(n=67)$ with HER2positive disease were selected by random assortment for the reference group who did not receive trastuzumab before surgery.

Results: The pathological complete response of study group was $(n=32) 50 \%$, which was $26.1 \%$ higher than the reference group $(n=16) 23.9 \%$; and this difference was statistically significant with a $p$-value of $0.002(<0.05)$. The overall pCR was $36.6 \%(n=48)$.

Conclusion: Addition of trastuzumab to neoadjuvant chemotherapy doubled the pCR in HER2-positive breast cancer. Targeted therapy should be offered to all eligible patients with HER2-overexpressing breast cancer.
\end{abstract}

Key Words: HER-2, Trastuzumab, Pathological complete response, Neoadjuvant chemotherapy.

\section{INTRODUCTION}

The human epidermal growth factor receptor 2 (HER2), previously called HER2/Neu or ERBB-2, belongs to the epidermal growth factor receptor (EGFR) family. These receptors are crucial for the activation of sub-cellular signal transduction pathways controlling epithelial cell growth and differentiation and possibly angiogenesis. 1 About $15-30 \%$ of all invasive breast cancers are HER2positive (overexpressing).2,3 Several studies have suggested that HER2-positive tumors are associated with aggressive disease, poor prognosis and have a higher risk of relapse than HER2-negative cancers.4-7

Addition of trastuzumab to adjuvant chemotherapy results in durable survival benefits for patients with

1 Department of Medical Oncology, Shaukat Khanum Memorial Cancer Hospital, Lahore, Pakistan

2 Department of Biostatistics and Epidemiology, Shaukat Khanum Memorial Cancer Hospital, Lahore, Pakistan

Correspondence: Dr. Fareeha Sheikh, Department of Medical Oncology, Shaukat Khanum Memorial Cancer Hospital,

7A Block R-3 M.A., Johar Town, Lahore, Pakistan

E-mail:fareeha8808@gmail.com

Received: April 19, 2018; Accepted: September 10, 2018
HER2-positive breast cancer. This was shown in the combined analysis of the North Central Cancer Treatment Group (NCCTG) N9831 trial and the National Adjuvant Breast and Bowel Project (NSABP) B-31 clinical trials. ${ }^{8}$ With a median on-study time of 8.4 years, the addition of trastuzumab resulted in a $37 \%$ improvement in the overall survival (OS) and a $40 \%$ improvement in disease-free survival. The first data for neoadjuvant trastuzumab came from a single centre, randomised study, which showed almost double pCR. ${ }^{9}$

The patients who achieved $\mathrm{pCR}$ after neoadjuvant treatment have a better long-term outcome.10,12 In a meta-analysis of 36 trials enrolling nearly 5800 patients with HER2-positive disease receiving neoadjuvant therapy, those who achieved a pCR (including breast and axilla) had superior event-free survival (EFS) and OS compared with those who did not. ${ }^{11}$ Consequently, increasing the rate of $\mathrm{PCR}$ became the endpoint of neoadjuvant trials with the expectation of translation into improved survival. Based on these results, FDA has given accelerated approval to drugs in neoadjuvant setting. ${ }^{11,13}$

Limited data is available regarding response of trastuzumab in Pakistani population, as majority of the patient population cannot get it due to cost issues. 
The purpose of this study was to determine the effectiveness of trastuzumab in the local population having HER-2 overexperssion, so that it can be used as a reference for future studies.

\section{METHODOLOGY}

The study was a retrospective, observational double-arm study. All patients receiving trastuzumab in neoadjuvant setting at Shaukat Khanum Memorial Cancer Hospital from 2008 to August 2016, fulfilling the inclusion criteria, were observed. The study protocols were reviewed by the Institutional Review Board and exemption was taken for informed consent as no direct interaction with patients was involved. Medical records were reviewed from the computer based hospital information system. The pre-aimed primary endpoint was to compare the pCR in HER-2 overexpressing breast cancer patients getting NACT with or without trastuzumab. The secondary endpoints were to study the frequency of breast conservation in patients getting trastuzumab preoperatively along with chemotherapy irrespective of the PCR; and added toxicities and influence of other baseline characteristics. Locally advanced HER2positive breast cancer patients with cytologically proven axillary nodes receiving standard NACT with or without trastuzumab were studied.

All patients had been tested for HER2-overexpression according to algorithms, developed by a joint consensus panel convened by the American Society of Clinical Oncology (ASCO) and the College of American Pathologists (CAP). Patients were eligible for neoadjuvant trastuzumab, if they had HER2-positive breast cancer defined as immunohistochemical (IHC) stain of $3+$ or FISH positive. The comparison group $(n=67)$ included randomly selected equal number of HER2positive breast cancer patients having similar tumor characteristics, getting neoadjuvant chemotherapy without trastuzumab.

A normal cardiac function had been documented at baseline by echocardiography; and cardiology opinion was taken for borderline cases before administration of trastuzumab, as it has a documented side effect of cardiotoxicity. Patients received four cycles of trastuzumab $6 \mathrm{mg} / \mathrm{kg}$ intravenously every 3 weeks, starting from a loading dose of $8 \mathrm{mg} / \mathrm{kg}$ in the first cycle or 12 doses of $2 \mathrm{mg} / \mathrm{kg}$ weekly with a loading dose of $4 \mathrm{mg} / \mathrm{kg}$ in the first cycle concomitantly with taxane-based therapy. Pathological complete response (pCR) was defined as no residual invasive or in situ residual tumor in breast tissue, or in the lymph nodes. ${ }^{14}$ Toxicities were assessed according to National Cancer Institute Common Terminology Criteria version 4.0. Lumpectomy or quadrantectomy and segmentectomy were stated as breast conservation procedures.

Data was collected through the computer-based Hospital Information System (HIS). Statistical analysis was performed by using SPSS version 20. For categorical variables, percentages (proportions) were reported as shown in Table I and II. Bivariate analysis was done using Chi-square or Fisher exact test, wherever appropriate, to establish the association between two categorical variables with $p<0.05$ considered as statistically significant. Univariable analysis was done to establish the relationship of one explanatory variable at a time with the outcome variable. The odds ratio, confidence interval, and $p$-value were calculated for each variable and reported in Table III column 4. In the multivariable analysis, statistical analysis was done by using step-wise regression method. All the factors with $p<0.05$ were considered statistically significant independent risk factors affecting pathological complete response. The odds ratio, confidence interval, and $p$-value were calculated for each variable and reported in Table III column 5.

\section{RESULTS}

During the study period, 89 patients with HER2-positive disease received trastuzumab preoperatively. Twenty patients $(22.5 \%)$ could not get the complete planned cycles of trastuzumab preoperatively due to financial

Table I: Baseline characteristics of patients with HER2-positive tumors treated with trastuzumab and a reference group of patients with HER2-positive tumors treated without trastuzumab.

\begin{tabular}{|c|c|c|}
\hline Characteristics & $\begin{array}{c}\text { Chemotherapy without } \\
\text { trastuzumab } \\
(n=67,51.2 \%)\end{array}$ & $\begin{array}{c}\text { Chemotherapy with } \\
\text { trastuzumab } \\
(n=64,48.8 \%)\end{array}$ \\
\hline \multicolumn{3}{|l|}{ Age, years } \\
\hline$\leq 40$ & $25(37.3 \%)$ & $19(30.2 \%)$ \\
\hline $41-50$ & $24(35.8 \%)$ & $19(30.2 \%)$ \\
\hline $51-60$ & $15(22.4 \%)$ & $20(31.7 \%)$ \\
\hline Above 60 & $3(4.5 \%)$ & $5(7.9 \%)$ \\
\hline \multicolumn{3}{|l|}{ Clinical tumor stage } \\
\hline cT1 & $1(1.49 \%)$ & $0(0.00 \%)$ \\
\hline cT2 & $33(49.25 \%)$ & $41(64.06 \%)$ \\
\hline cT3 & $10(14.93 \%)$ & $7(10.94 \%)$ \\
\hline cT4 & $22(32.84 \%)$ & $15(23.44 \%)$ \\
\hline cTx & $1(1.49 \%)$ & $1(1.56 \%)$ \\
\hline \multicolumn{3}{|l|}{ Stage } \\
\hline$I I A+B$ & $39(58.2 \%)$ & $45(72.6 \%)$ \\
\hline III A & $13(19.4 \%)$ & $8(12.9 \%)$ \\
\hline III B & $12(17.9 \%)$ & $9(14.5 \%)$ \\
\hline III C & $3(4.5 \%)$ & $0(0 \%)$ \\
\hline \multicolumn{3}{|l|}{ Tumor grade } \\
\hline 2 & $23(34.3 \%)$ & $29(45.3 \%)$ \\
\hline 3 & $44(65.7 \%)$ & $35(54.7 \%)$ \\
\hline \multicolumn{3}{|l|}{ Tumor histology } \\
\hline Ductal invasive & $59(88.06)$ & $57(89.06 \%)$ \\
\hline Lobular invasive & $1(1.49 \%)$ & $1(1.56 \%)$ \\
\hline Others & $7(10.45 \%)$ & $6(9.38 \%)$ \\
\hline \multicolumn{3}{|l|}{ ER/PgR status } \\
\hline ER negative/PgR negative & $41(61.2 \%)$ & $24(37.5 \%)$ \\
\hline ER positive/PgR positive & $16(23.9 \%)$ & $27(42.2 \%)$ \\
\hline ER positive/PgR negative & $10(14.9 \%)$ & $11(17.2 \%)$ \\
\hline ER negative/PgR positive & $0.00(0.00)$ & $2(3.1 \%)$ \\
\hline
\end{tabular}


Table II: National Cancer Institute common toxicity criteria (version 4.0). Grading of adverse events of patients receiving neoadjuvant chemotherapy with or without trastuzumab.

\begin{tabular}{|c|c|c|c|}
\hline Symptom & Grading & $\begin{array}{c}\text { Chemotherapy } \\
\text { without trastuzumab } \\
(\mathrm{n}=67,51.2 \%)\end{array}$ & $\begin{array}{c}\text { Chemotherapy } \\
\text { with trastuzumab } \\
(n=64,48.8 \%)\end{array}$ \\
\hline \multirow[t]{5}{*}{ Mucosits } & No mucositis & $40(59.7 \%)$ & $29(45.3 \%)$ \\
\hline & Grade 1 & $12(17.9 \%)$ & $13(20.3 \%)$ \\
\hline & Grade 2 & $13(19.4 \%)$ & $20(31.2 \%)$ \\
\hline & Grade 3 & $2(3 \%)$ & $2(3.2 \%)$ \\
\hline & Grade 4 & $0(0.0 \%)$ & $0(0.0 \%)$ \\
\hline \multirow[t]{5}{*}{ Diarrhea } & No diarrhea & $54(80.6 \%)$ & $50(78.1 \%)$ \\
\hline & Grade 1 & $2(3 \%)$ & $5(7.8 \%)$ \\
\hline & Grade 2 & $11(16.4 \%)$ & $7(10.9 \%)$ \\
\hline & Grade 3 & $0(0.0 \%)$ & $2(3.2 \%)$ \\
\hline & Grade 4 & $0(0.0 \%)$ & $0(0.0 \%)$ \\
\hline \multirow[t]{5}{*}{ Vomiting } & No vomiting & $44(65.7 \%)$ & $50(78.1 \%)$ \\
\hline & Grade 1 & $17(25.3 \%)$ & $4(6.3 \%)$ \\
\hline & Grade 2 & $6(9.0 \%)$ & $10(15.6 \%)$ \\
\hline & Grade 3 & $0(0.0 \%)$ & $0(0.0 \%)$ \\
\hline & Grade 4 & $0(0.0 \%)$ & $0(0.0 \%)$ \\
\hline \multirow[t]{5}{*}{ Rash } & No rash & $59(88.1 \%)$ & $60(93.7 \%)$ \\
\hline & Grade 1 & $6(8.9 \%)$ & $1(1.6 \%)$ \\
\hline & Grade 2 & $1(1.5 \%)$ & $2(3.1 \%)$ \\
\hline & Grade 3 & $1(1.5 \%)$ & $1(1.6 \%)$ \\
\hline & Grade 4 & $0(0.0 \%)$ & $0(0.0 \%)$ \\
\hline \multirow[t]{5}{*}{ Neuropathy } & No neuropathy & $53(79.1 \%)$ & $43(67.2 \%)$ \\
\hline & Grade 1 & $12(17.9 \%)$ & $12(18.7 \%)$ \\
\hline & Grade 2 & $2(3.0 \%)$ & $5(7.8 \%)$ \\
\hline & Grade 3 & $0(0.0 \%)$ & $4(6.3 \%)$ \\
\hline & Grade 4 & $0(0.0 \%)$ & $0(0.0 \%)$ \\
\hline \multirow[t]{5}{*}{ Drop in $\mathrm{EF}^{*}$} & No Drop in EF* & $60(89.5 \%)$ & $62(96.9 \%)$ \\
\hline & Grade 1 & $4(6.0 \%)$ & $0(0.0 \%)$ \\
\hline & Grade 2 & $2(3.0 \%)$ & $2(3.1 \%)$ \\
\hline & Grade 3 & $1(1.5 \%)$ & $0(0.0 \%)$ \\
\hline & Grade 4 & $0(0.0 \%)$ & $0(0.0 \%)$ \\
\hline \multirow[t]{4}{*}{ Febrile neutropenia } & $\begin{array}{l}\text { No Febrile } \\
\text { Neutropenia } \\
\text { Grade } 1\end{array}$ & $\begin{array}{c}54(80.6 \%) \\
0(0.0 \%)\end{array}$ & $\begin{array}{c}55(85.9 \%) \\
0(0.0 \%)\end{array}$ \\
\hline & Grade 2 & $0(0.0 \%)$ & $0(0.0 \%)$ \\
\hline & Grade 3 & $13(19.4 \%)$ & $9(14.1 \%)$ \\
\hline & Grade 4 & $0(0.0 \%)$ & $0(0.0 \%)$ \\
\hline
\end{tabular}

reasons or delayed approval while surgery could not be done in one $(1.12 \%)$ patient due to disease progression while on therapy. Four $(4.5 \%)$ patients had to undergo surgery earlier due to poor tolerance of chemotherapy. The study group, therefore, comprised $64 \quad(n=64)$ patients who received full dose of neoadjuvant trastuzumab.

The overall $p C R$ in entire population was $(n=48) 36.6 \%$. The $\mathrm{pCR}$ of the patients who received trastuzumab in the neoadjuvant setting was $(n=32) 50 \%$, which was $26.1 \%$ higher than the reference group $(n=16) 23.9 \%$. This difference was statistically significant with a p-value of $0.002(<0.05)$. Breast conservation was possible in 57 $(43.51 \%)$ patients in total and $51.56 \%$ in patients getting trastuzumab preoperatively as compared to $35.82 \%$ in patients who received chemotherapy alone. $\mathrm{P}$-value was calculated as 0.69 which although was not statistically significant, but still a considerable number of patients had a less extensive surgery.

Toxicities were documented according to National Cancer Institute Common Toxicity Criteria (version 4.0) grading of adverse events by reviewing the records in the computer-based Hospital Information System. By adding trastuzumab, there were no major differences in the toxicity profiles of both groups as shown in Table II. The drop in ejection fraction, which is a major concern with the addition of trastuzumab, was also almost equal in both groups with no major differences. No patient developed symptomatic heart failure and none had to stop trastuzumab before completing the planned therapy.

\section{DISCUSSION}

This study demonstrated that HER2-positive (overexpressing) breast cancer patients, who received preoperative trastuzumab in combination with standard chemotherapeutic regimens, achieved significantly higher rates of $\mathrm{pCR}$ as compared to those who got chemotherapy alone. According to protocol pre-defined definition the $\mathrm{pCR}$ in entire patient population was $36.6 \%$. Patients who received trastuzumab in the neoadjuvant setting had pCR of $50 \%$, which was $26.1 \%$ higher than the reference group $(23.9 \%)$, which is almost double in comparison. This response is significantly higher than the previously conducted international studies like GparQuattro study having a complete response rate of $31.7 \%$ in patients getting preoperative trastuzumab. 15 Similarly, transtuzumab in neoadjuvant setting in newly diagnosed locally advanced HER2positive breast cancer patients has been studied in TECHNO trial which was a phase II single-arm study which showed a complete response rate of $39 \% .{ }^{16}$ The $\mathrm{NOAH}$ trial demonstrated a pCR rate of $43 \%$ in neoadjuvant trastuzumab combination group as compared to $22 \%$ in the chemotherapy alone group. ${ }^{17} \mathrm{~A}$ recent study in the local population demonstrated the similar response rates of $54.8 \%$ comparable to this study population. ${ }^{18}$

Compared to all the above mentioned studies, this study has demonstrated a notably high $\mathrm{pCR}$ in these patients and can be future perspective for further studies. One possible reason for the better response can be the factor that all node-positive patients were included, depicting a better response in this high risk population. Although a single study at an individual centre with a small number of patients cannot be a true representative of the entire population, it definitely provides an insight for more studies so that possible causes of increased response in the local population can be studied. Different mechanisms of resistance to trastuzumab therapy have been studied including loss of PTEN and are thought to promote tumorigenesis by activating $\mathrm{PI} 3 \mathrm{~K}$ signalling 
Table III: Factors associated with pCR in patients with HER2-positive tumors.

\begin{tabular}{|c|c|c|c|c|c|}
\hline \multirow[b]{2}{*}{ Factors } & \multirow[b]{2}{*}{ Category } & \multicolumn{2}{|c|}{ Response } & \multirow{2}{*}{$\begin{array}{c}\text { Univariable analysis } \\
\text { odds ratio }(95 \% \mathrm{Cl}), \mathrm{p} \text {-value }\end{array}$} & \multirow{2}{*}{$\begin{array}{l}\text { Multivariable variable analysis } \\
\text { odds ratio }(95 \% \mathrm{Cl}), \mathrm{p} \text {-value }\end{array}$} \\
\hline & & $\begin{array}{c}\text { Yes } \\
48(36.6 \%)\end{array}$ & $\begin{array}{c}\text { No } \\
83(63.4 \%)\end{array}$ & & \\
\hline Age in years & $\begin{array}{c}\leq 40 \\
41-50 \\
51-60 \\
\text { Above } 60\end{array}$ & $\begin{array}{c}16(33.3 \%) \\
12(25.0) \\
16(33.3) \\
4(8.3 \%) \\
\end{array}$ & $\begin{array}{c}28(34.1 \%) \\
31(37.8 \%) \\
19(23.2 \%) \\
4(4.9 \%) \\
\end{array}$ & $\begin{array}{c}\text { Ref } \\
1.47(0.593 .64), 0.40 \\
0.68 \text { (0.27 1.68), } 0.40 \\
0.57 \text { (0.12 2.60), } 0.47\end{array}$ & $\begin{array}{c}\text { Ref } \\
1.88(0.655 .41), 0.24 \\
0.97(0.342 .76), 0.95 \\
0.84(0.135 .25), 0.85\end{array}$ \\
\hline Histologic type & $\begin{array}{c}\text { Lobular invasive } \\
\text { Ductal invasive } \\
\text { Others }\end{array}$ & $\begin{array}{c}1(2.1 \%) \\
42(87.5 \%) \\
5(10.4 \%) \\
\end{array}$ & $\begin{array}{c}1(1.2 \%) \\
74(89.2 \%) \\
8(9.6 \%) \\
\end{array}$ & $\begin{array}{c}\text { Ref } \\
1.76(0.1028 .90), 0.69 \\
1.60(0.0831 .77), 0.76\end{array}$ & $\begin{array}{c}\text { Ref } \\
1.24(0.0292 .83), 0.92 \\
0.79(0.0175 .39), 0.92\end{array}$ \\
\hline Grading & $\begin{array}{l}\text { Grade } 2 \\
\text { Grade } 3\end{array}$ & $\begin{array}{l}20(41.7 \%) \\
28(58.3 \%)\end{array}$ & $\begin{array}{l}32(38.6 \%) \\
51(61.4 \%)\end{array}$ & $\begin{array}{c}\text { Ref } \\
1.14(0.552 .35), 0.73\end{array}$ & $\begin{array}{c}\text { Ref } \\
0.88(0.372 .09), 0.77\end{array}$ \\
\hline Stage & $\begin{array}{l}\text { II A+B } \\
\text { III A } \\
\text { III B } \\
\text { III C }\end{array}$ & $\begin{array}{c}26(56.5 \%) \\
6(13.0 \%) \\
14(30.4 \%) \\
0(0.0 \%)\end{array}$ & $\begin{array}{c}58(69.9 \%) \\
15(18.1 \%) \\
7(8.4 \%) \\
3(3.6 \%)\end{array}$ & $\begin{array}{c}\text { Ref } \\
1.12(0.393 .21), 0.83 \\
0.22(0.080 .62), 0.004 \\
\text { NA }\end{array}$ & $\begin{array}{c}\text { Ref } \\
1.18(0.363 .87), 0.78 \\
0.16(0.050 .51), 0.002 \\
\text { NA }\end{array}$ \\
\hline ER/PgR status & $\begin{array}{l}\text { ER negative/PgR negative } \\
\text { ER positive/PgR positive } \\
\text { ER positive/PgR negative } \\
\text { ER negative/PgR positive }\end{array}$ & $\begin{array}{c}21(43.8 \%) \\
16(33.3 \%) \\
10(20.8 \%) \\
1(2.1 \%)\end{array}$ & $\begin{array}{c}44(53.0 \%) \\
27(32.5 \%) \\
11(13.3 \%) \\
1(1.2 \%)\end{array}$ & $\begin{array}{c}\text { Ref } \\
0.80(0.361 .81), 0.60 \\
0.52(0.191 .43), 0.21 \\
0.48(0.038 .01), 0.61\end{array}$ & $\begin{array}{c}\text { Ref } \\
0.90(0.352 .33), 0.84 \\
0.59(0.191 .82), 0.36 \\
2.16(0.0954 .66), 0.64\end{array}$ \\
\hline Neoadjuvant trastuzumab & $\begin{array}{l}\text { No } \\
\text { Yes }\end{array}$ & $\begin{array}{l}16(33.3 \%) \\
32(66.7 \%)\end{array}$ & $\begin{array}{l}51(61.4 \%) \\
32(38.6 \%)\end{array}$ & $\begin{array}{c}\text { Ref } \\
0.31(0.150 .66), 0.002\end{array}$ & $\begin{array}{c}\text { Ref } \\
0.28(0.110 .67), 0.004\end{array}$ \\
\hline
\end{tabular}

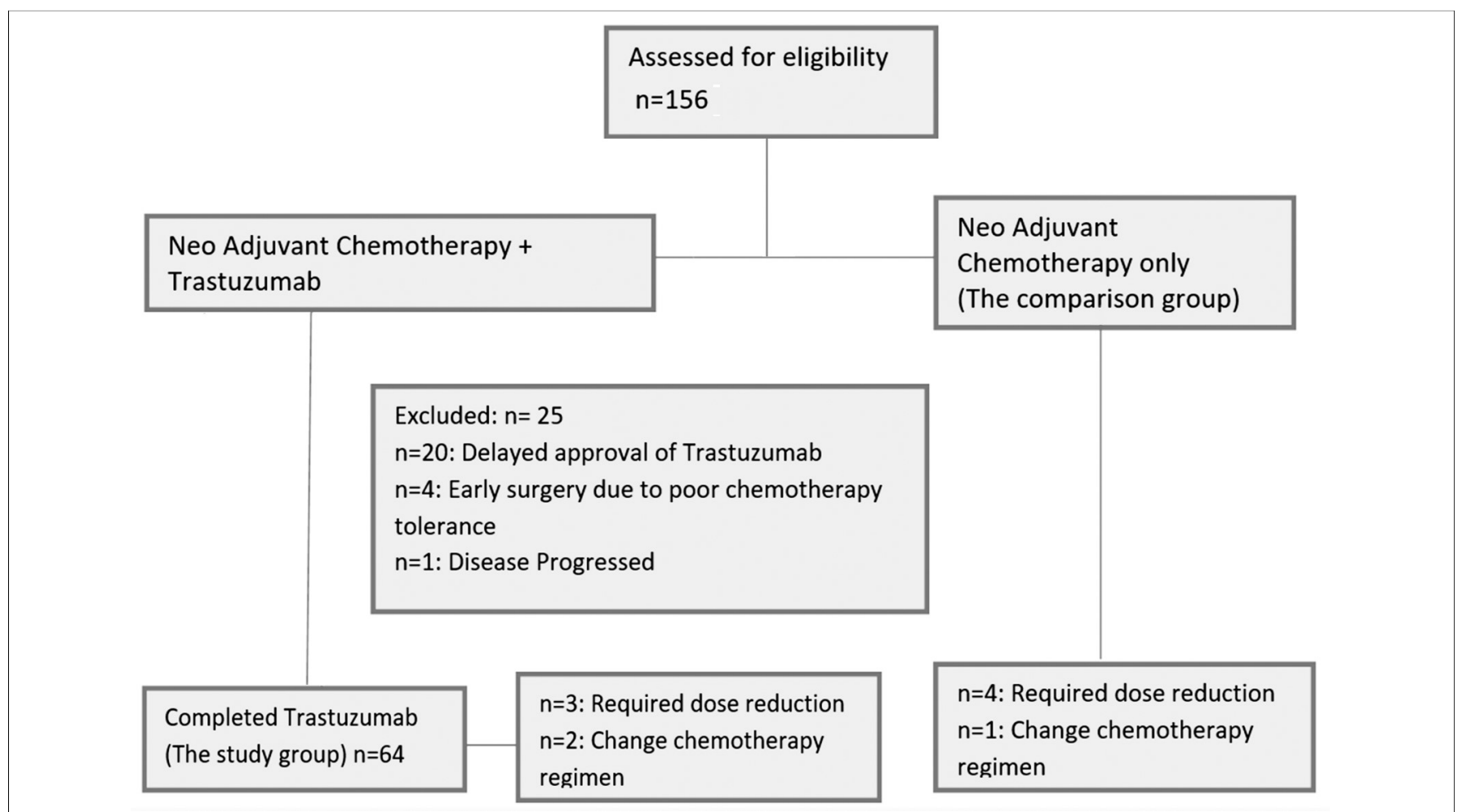

Figure 1: Consort diagram of patients.

pathway. ${ }^{19}$ Since this study population has demonstrated a quite high response, studies are needed to look for genetic factors in our people which render our patients more susceptible to response to trastuzumab-based therapy like PTEN expression. ${ }^{20}$ Although the study demonstrated a significantly higher pathological response in the neoadjuvant trastuzumab group, breast conservation rate was not significantly different in both the patient groups, but less extensive surgery was possible in notable number of patients. Regarding toxicity profile, the addition of trastuzumab to standard chemotherapeutic regimens did not significantly increase the toxicity profile as compared to chemotherapy alone. 
This study has several weaknesses. Firstly, it is a retrospective study, so all patients did not receive similar chemotherapeutic regimens. However, this was uniform for both study arms. It included a small number of patients; had it included a greater number of patients, results would have been more powerful. However, since all patients fulfilling the inclusion criteria were included, so there was no selection bias. Hence, results are likely depictive of response in our population.

\section{CONCLUSION}

Combining trastuzumab with standard chemotherapy regimens in HER2-positive achieves significantly higher rate of pathological complete response without clinically significant increased toxicity. Further studies with larger number of patients are required to demonstrate mechanisms leading to better responses in this population and whether this increased response can be translated into increased survival rates.

\section{REFERENCES}

1. Burstein HJ. The distinctive nature of HER2-positive breast cancers. New Engl J Med 2005; 353:1652-4.

2. Mitri Z, Constantine T, O'Regan R. The HER2 receptor in breast cancer: pathophysiology, clinical use, and new advances in therapy. Chemother Res Pract 2012; 2012; 743193.

3. Anderson WF, Rosenberg PS, Katki HA. Tracking and evaluating molecular tumor markers with cancer registry data: HER2 and breast cancer. J Natl Cancer Inst Monogr 2014; 106.dju093.

4. Curigliano G, Viale G, Bagnardi V, Fumagalli L, Locatelli M, Rotmensz $\mathrm{N}$, et al. Clinical relevance of HER2 overexpression/amplification in patients with small tumor size and node-negative breast cancer. J Clin Oncol 2009; 27:5693-9.

5. Gonzalez-Angulo AM, Litton JK, Broglio KR, Meric-Bernstam F, Rakkhit R, Cardoso F, et al. High risk of recurrence for patients with breast cancer who have human epidermal growth factor receptor 2-positive, node-negative tumors $1 \mathrm{~cm}$ or smaller. J Clin Oncol 2009; 27:5700-6.

6. Rouanet P, Roger P, Rousseau E, Thibault S, Romieu G, Mathieu $A$, et al. HER2 overexpression a major risk factor for recurrence in pT1a-bNOM0 breast cancer: results from a French regional cohort. Cancer Med 2014; 3:134-42.

7. Ferretti G, Felici A, Papaldo P, Fabi A, Cognetti F. HER2/neu role in breast cancer: From a prognostic foe to a predictive friend. Cur Opin Obstet Gynecol 2007; 19:56-62.

8. Perez EA, Romond EH, Suman VJ, Jeong JH, Sledge G, Geyer Jr CE, et al. Trastuzumab plus adjuvant chemotherapy for human epidermal growth factor receptor 2-positive breast cancer: planned joint analysis of overall survival from NSABP B-31 and NCCTG N9831. J Clini Oncol 2014; 32:3744-52.

9. Buzdar AU, Ibrahim NK, Francis D, Booser DJ, Thomas ES, Theriault RL, et al. Significantly higher pathologic complete remission rate after neoadjuvant therapy with trastuzumab, paclitaxel, and epirubicin chemotherapy: results of a randomized trial in human epidermal growth factor receptor 2-positive operable breast cancer. J Clin Oncol 2005; 23: 3676-85.

10. Gianni L, Eiermann W, Semiglazov V, Lluch A, Tjulandin S, Zambetti $\mathrm{M}$, et al. Neoadjuvant and adjuvant trastuzumab in patients with HER2-positive locally advanced breast cancer (NOAH): follow-up of a randomised controlled superiority trial with a parallel HER2-negative cohort. Lancet Oncol 2014; 15:640-7.

11. Broglio KR, Quintana M, Foster M, Olinger M, McGlothlin A, Berry SM, et al. Association of pathologic complete response to neoadjuvant therapy in HER2-positive breast cancer with long-term outcomes: a meta-analysis. JAMA Oncol 2016; 2:751-60.

12. Spring L, Greenup R, Reynolds K, Smith BL, Moy B, Bardia A. Pathological complete response after neoadjuvant chemotherapy predicts improved survival in all major subtypes of breast cancer: systematic review and meta-analyses of over 18,000 patients. 2016 AACR Annual Meeting. Abstract presented April 18, 2016.

13. Prowell TM, Pazdur R. Pathological complete response and accelerated drug approval in early breast cancer. New Engl $J$ Med 2012; 366:2438-41.

14. Cortazar P, Zhang L, Untch M, Mehta K, Costantino JP, Wolmark $\mathrm{N}$, et al. Pathological complete response and longterm clinical benefit in breast cancer: the CTNeoBC pooled analysis. Lancet 2014; 384:164-72.

15. Untch M, Rezai M, Loibl S, Fasching PA, Huober J, Tesch H, et al. Neoadjuvant treatment with trastuzumab in HER2positive breast cancer: Results from the GeparQuattro study. J Clin Oncol 2010; 28:2024-31.

16. Untch M, Fasching PA, Konecny GE, Hasmüller S, Lebeau A, Kreienberg $\mathrm{R}$, et al. Pathologic complete response after neoadjuvant chemotherapy plus trastuzumab predicts favorable survival in human epidermal growth factor receptor 2-overexpressing breast cancer: results from the TECHNO trial of the AGO and GBG study groups. J Clin Oncol 2011; 29: 3351-7.

17. Gianni L, Eiermann W, Semiglazov V, Manikhas A, Lluch A, Tjulandin $S$, et al. Neoadjuvant chemotherapy with trastuzumab followed by adjuvant trastuzumab versus neoadjuvant chemotherapy alone, in patients with HER2positive locally advanced breast cancer (the NOAH trial): a randomised controlled superiority trial with a parallel HER2negative cohort. Lancet 2010; 375:377-84.

18. Zeeshan S, Khan SM, Khan N. Pathologic tumor response and long term outcome with neoadjuvant trastuzumab in Her-2 positive breast cancer. Ann Oncol 2016; 27 :mdw576.006.

19. Gajria D, Chandarlapaty S. HER2-amplified breast cancer: mechanisms of trastuzumab resistance and novel targeted therapies. Expert Rev Anticancer Ther 2011; 11:263-75.

20. Stern HM, Gardner H, Burzykowski T, Elatre W, O'Brien C, Lackner MR, et al. PTEN loss is associated with worse outcome in HER2-amplified breast cancer patients but is not associated with trastuzumab resistance. Clin Cancer Res 2015; 21:2065-74.

-....... 